\title{
Determination of product density for calculating the safety pressure on the walls of sieve drum in pulping machine
}

\author{
Andrey V. Bogdanov ${ }^{1}$, Svetlana Y u. Popova ${ }^{1,{ }^{*}}$, and Lyubov A. Stricker ${ }^{1}$ \\ ${ }^{1}$ South U ral State A grarian University, 454080, Chelyabinsk, Russia
}

\begin{abstract}
Pulping machines are an integral part of production lines for the processing fruits and vegetables. To meet the ever-growing demand for these agricultural products, it is necessary to introduce innovative solutions to modernize equipment not only for increasing its productivity but also for ensuring its safety. The article proposes a pulping machine that helps to increase the productivity by using the entire area of the sieve drum. The productivity also depends on reliable and safe equipment operation, elimination of downtime during product pulping. One of the main factors affecting the reliable and safe operation is the pressure of pulped product on the walls of the sieve drum, and this pressure depends on the product density. It has been experimentally shown that the density of pulped product can vary significantly even for different varieties of vegetable marrow. As the calculations show, in this case the pressure inside the sieve drum of the pulping machine changes considerably (more than 10\%). Therefore, the density of the product should be taken into account when calculating the design parameters of the pulping machine; it helps to ensure its reliable and safe operation and hence to reduce the probability of downtime and to improve the productivity.
\end{abstract}

\section{Relevance}

A t present fruit and vegetable purees, juices and other products obtained through the processing of fruits and vegetables are in great demand all over the world [1,2]. Production lines for processing fruit and vegetable products consist of various equipment: washing machines, cleaning machines, blanchers, grinding machines $[3,4]$. The latter include plumping machines.

Plumping machines are represented by a large range of constructive forms and purposes [5, 6]. To meet the ever-growing demand for vegetables and fruits, it is necessary to introduce innovative solutions to modernize existing equipment not only for increasing its productivity but also for ensuring its safety [7].

In this regard, a pulping machine which helps to increase the productivity has been developed at the department "Processing of agricultural products and life safety" in South U ral State A grarian U niversity, and a patent for this machine has been received (Fig. 1) [8].

${ }^{*}$ Corresponding author: vetochka.79@ mail.ru 


\section{Test object and equipment}

The pulping machine operates as follows (Fig. 1). The processed raw material is fed to the basket through the loading nozzle. Rotated by the shaft the screw displacing piston due to its conical shape more evenly distributes the pressure of the raw material along the periphery of the cylindrical sieve drum installed inside the basket. The friction of the raw material on the surface of the cylindrical sieve drum results in its grating and falling into the space between the drum and the basket, there under the force of gravity the grated raw material falls through the holes of the basket into the gathering bin. Non-grated waste (peels, kernels, seeds, etc.) are removed through unloading chute, where they are delivered by means of agitator. Then the grated product is taken from the gathering bin [8]. Thus, the increase in productivity is achieved by using the entire area of the sieve drum.

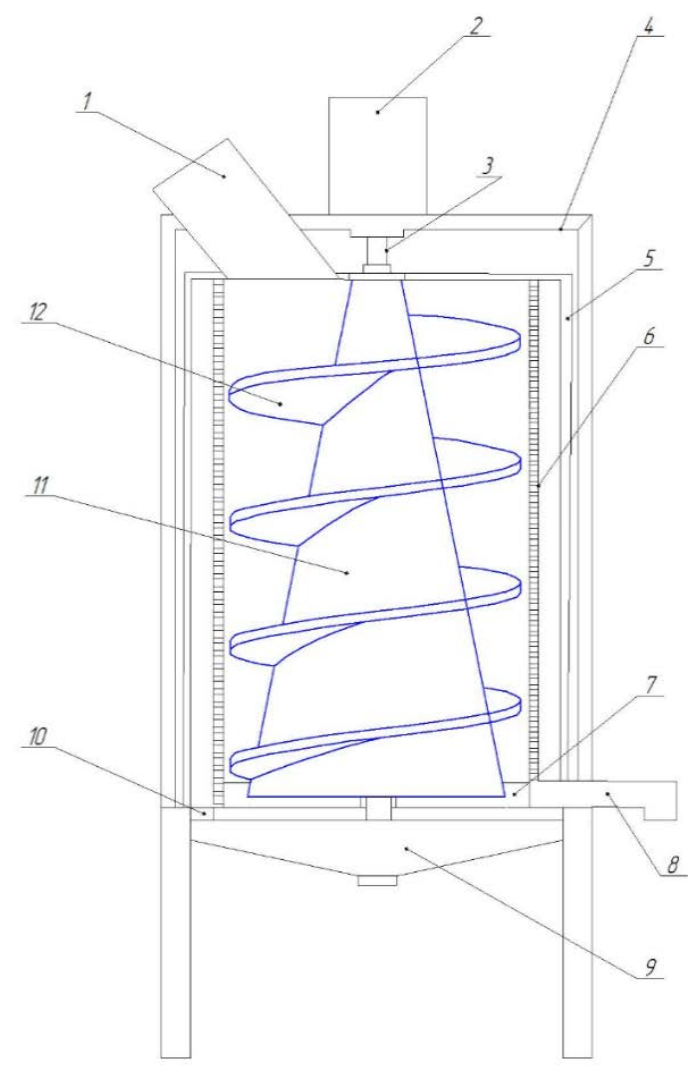

Fig. 1. Pulping machine: 1 - loading nozzle; 2 - electric motor; 3 - shaft; 4 - case; 5 - basket; 6 - cylindrical sieve drum; 7 - agitator; 8 - unloading chute; 9 - gathering bin; 10 - holes for penetration of grated raw material into gathering bin; 11 - screw displacing piston; $12 \pm$ blades

The productivity of this pulping machine also depends on its reliable and safe operation, which eliminates downtime during the process of product pulping. One of the main factors affecting the reliable and safe operation is the pressure of pulped product on the walls of the sieve drum. When the pressure increases, the walls of the sieve drum can be deformed; it can result in breakdown of equipment and possibly an emergency, injury to staff, etc. [9]. Therefore, the pressure value is important for proper operation of pulping machine and can be calculated at the stage of its designing according to the following dependency [10]: 


$$
P_{o p}=\frac{\omega^{2} \cdot r_{r} \cdot \varphi \cdot \rho \cdot\left(r_{s}^{2}-r_{r}^{2}\right)}{2 \cdot r_{s}}, M P a
$$

where $\omega$ is the circumferential speed of the conical auger, $\mathrm{rad} / \mathrm{s} ; r_{r}$ is the rotor radius (the average radius of the conical auger), $m ; \varphi$ is the filling factor of the gap between the blades of the auger and the sieve drum; $\rho$ is the density of the processed raw materials, $\mathrm{kg} / \mathrm{m}^{3} ; \mathrm{r}_{\mathrm{s}}$ is the stator radius (sieve drum radius), $m$.

A s can be seen from the formula (1), with all other conditions being equal, the pressure value on the walls of the sieve drum depends on the density $\rho$ of the pulped product (processed raw material). M oreover, for different raw materials the density $\rho$ can vary widely $[11,12]$. Even for the different varieties of vegetable marrow, the value of their density can vary significantly. A vailable information about the density of vegetable marrow does not al ways correspond to real values. Therefore, we carried out experimental laboratory studies with vegetable marrow of two varieties: Gribovskiy and Tsukesha [13].

The determination of density in the varieties Gribovskiy and Tsukesha was carried out according to the following procedure: a cube with a certain side length was cut out from the flesh of vegetable marrow. A caliper, which was made in $\mathrm{CHIZ}$ plant, was used for measuring the length of cube sides. Then each cube cut from vegetable marrow flesh was weighed using PetV es NV 600 scales (Fig. 2). The measurements were carried out with a fivefold repetition. Tables 1 and 2 present the results of experimental studies and the values of density $\rho$ and the average density $\rho_{a v}$ of the vegetable marrow flesh according to the well-known formulas [14, 15]:

$$
\rho=\frac{m}{V}
$$

where $m$ is the cube mass of vegetable marrow flesh, $\mathrm{kg} ; V$ is the cube volume of vegetable marrow flesh, $\mathrm{m}^{3}$.

$$
\rho_{a v}=\frac{\sum_{i=1}^{n} \rho_{i}}{n},
$$

where $n$ is the number of experiments; $\rho_{i}$ is the density of vegetable marrow flesh during the $\mathrm{i}$-th experiment, $\mathrm{kg} / \mathrm{m}^{3}$.

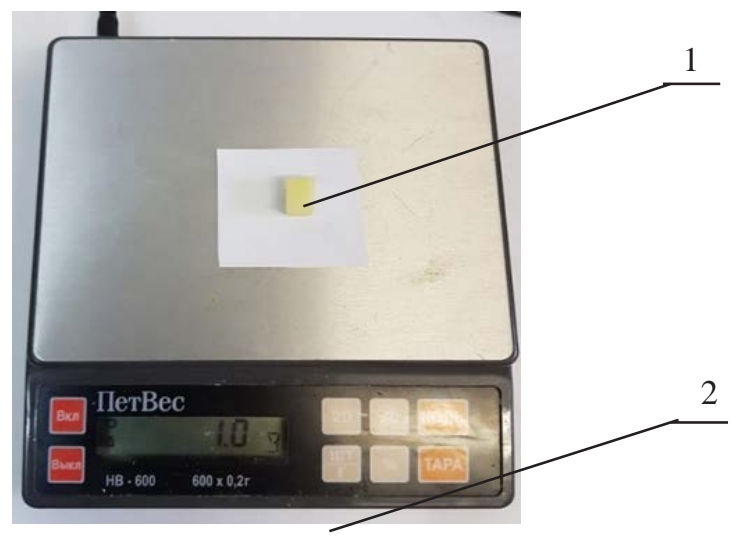

Fig. 2. M easurement of a cube cut out from vegetable marrow flesh: 1 - is a cube cut out from vegetable marrow flesh; 2 - is PetV es NV -600 scales 
Table 1. The results of experimental studies of the variety Tsukesha

\begin{tabular}{|c|c|c|c|c|c|c|c|}
\hline $\begin{array}{l}\text { Item } \\
\text { No. }\end{array}$ & $\begin{array}{l}\text { Side length of } \\
\text { vegetable mar- } \\
\text { row cube, cm }\end{array}$ & $\begin{array}{c}\text { Volume, } \\
\mathrm{cm}^{3}\end{array}$ & $\begin{array}{c}\text { Volume, } \\
\mathrm{m}^{3}\end{array}$ & $\begin{array}{c}M \text { ass } \\
m, g\end{array}$ & M ass $\mathrm{m}, \mathrm{kg}$ & $\begin{array}{l}\text { Density } \\
\rho, \mathrm{kg} / \mathrm{m}^{3}\end{array}$ & $\begin{array}{c}\text { A verage } \\
\text { density } \\
\rho_{\text {av }}, \mathrm{kg} / \mathrm{m}^{3}\end{array}$ \\
\hline 1. & 0.8 & 0.51 & 0.00051 & 0.5 & 0.0005 & 0.98 & \multirow{5}{*}{0.982} \\
\hline 2. & 1.0 & 1.0 & 0.00100 & 1.0 & 0.0010 & 1.00 & \\
\hline 3. & 1.2 & 1.73 & 0.00173 & 1.6 & 0.0016 & 0.93 & \\
\hline 4. & 1.3 & 2.20 & 0.00220 & 2.2 & 0.0022 & 1.00 & \\
\hline 5. & 1.5 & 3.38 & 0.00380 & 3.8 & 0.0038 & 1.00 & \\
\hline
\end{tabular}

Table 2. The results of experimental studies of the variety Gribovskiy

\begin{tabular}{|c|c|c|c|c|c|c|c|}
\hline $\begin{array}{c}\text { Ite } \\
\text { m } \\
\text { No. }\end{array}$ & $\begin{array}{l}\text { Side length of } \\
\text { vegetable mar- } \\
\text { row cube, cm }\end{array}$ & $\begin{array}{c}\text { Volume, } \\
\mathrm{cm}^{3}\end{array}$ & $\begin{array}{c}\text { Volume, } \\
\mathrm{m}^{3}\end{array}$ & $\begin{array}{c}M \text { ass } \\
m, g\end{array}$ & M ass $\mathrm{m}, \mathrm{kg}$ & $\begin{array}{c}\text { Density } \\
\rho, \mathrm{kg} / \mathrm{m}^{3}\end{array}$ & $\begin{array}{c}\text { A verage } \\
\text { density } \\
\rho_{\mathrm{av}}, \mathrm{kg} / \mathrm{m}^{3}\end{array}$ \\
\hline 1. & 0.8 & 0.51 & 0.00051 & 0.4 & 0.0004 & 0.78 & \multirow{5}{*}{0.876} \\
\hline 2. & 1.0 & 1.0 & 0.00100 & 0.9 & 0.0009 & 0.90 & \\
\hline 3. & 1.2 & 1.73 & 0.00173 & 1.5 & 0.0015 & 0.86 & \\
\hline 4. & 1.3 & 2.20 & 0.00220 & 2.3 & 0.0023 & 1.05 & \\
\hline 5. & 1.5 & 3.38 & 0.00338 & 3.0 & 0.0030 & 0.79 & \\
\hline
\end{tabular}

\section{Theoretical substantiation}

As you can see in the tables, the average density $\rho_{a v}$ of the varieties Gribovskiy and Tsukesh is significantly different; according to formula (1) this will affect the pressure inside the sieve drum of the pulping machine. The change in pressure $\Delta$ in percentage terms for these varieties of vegetable marrow can be determined as follows:

$$
\Delta=\frac{P_{g r}}{P_{t s u k}} \cdot 100 \%,
$$

where $P_{g r}$ is the pressure of the product (vegetable marrow of the Gribovskiy variety) on the walls of the sieve drum, $\mathrm{N}$; $P_{\text {tsuk }}$ is the pressure of the product (vegetable marrow of the $T s u$ kesha variety) on the walls of the sieve drum, $\mathrm{N}$.

The pressure inside the sieve drum (other conditions being equal) for the Gribovskiy and Tsukesha varieties can be found on the basis of expression (1):

$$
\begin{aligned}
P_{g r} & =\frac{\omega^{2} \cdot r_{r} \cdot \varphi \cdot \rho_{g r} \cdot\left(r_{s}^{2}-r_{r}^{2}\right)}{2 \cdot r_{s}} ; \\
P_{t s u k} & =\frac{\omega^{2} \cdot r_{r} \cdot \varphi \cdot \rho_{t s u k} \cdot\left(r_{s}^{2}-r_{r}^{2}\right)}{2 \cdot r_{s}},
\end{aligned}
$$

where $\rho_{g r}$ is the density of the product (vegetable marrow of the Gribovskiy variety), $\mathrm{kg} / \mathrm{m}^{3}$; $\rho_{t s u k}$ is the density of the product (vegetable marrow of the Tsukesha variety), $\mathrm{kg} / \mathrm{m}^{3}$.

Then considering expressions (5) and (6) the formula (4) will take the form: 


$$
\Delta=\frac{\rho_{g r}}{\rho_{\text {tsuk }}} \cdot 100 \% .
$$

Substituting the corresponding average density values for the Gribovskiy and Tsukesha varieties (Tables 1 and 2 ) instead of the values $\rho_{g r}$ and $\rho_{\text {tsuk }}$ into the formula (7), we get:

$$
\Delta=\frac{0,876}{0,982} \cdot 100 \%=89,2 \%
$$

\section{Conclusion}

A s we can see from the above cal culation, the pressure inside the si eve drum of pulping machine changes considerably (more than 10\%) for different vegetable marrow varieties. This should be taken into account when calculating the design parameters of pulping machine, since this can ensure its reliable and safe operation and therefore reduce the probability of downtime and increase the productivity.

\section{References}

1. S.M. Ryzhkova, Development of fruit and vegetable market in the Russian Federation, 163 p, ( 2015)

2. V.M. Cherkasova, About conditions, problems and development trends of fruit and vegetable industry in the Russian Federation, Food Industry, No 3, p. 34-35 (2001)

3. V.A. Sharshunov, D.A. Smagin, Technological equipment of fruit and vegetable processing enterprises: Equipment for preparing raw materials for processing, v. 1, 969 p. (2013)

4. V.P. Zolin, Technological equipment of public catering enterprises, 256 p. (2000)

5. E.P. Shirokov, Technology of storage and processing of vegetables with the basics of standardization (2008)

6. S.T. A ntipov, Processes and equipment of food production. Machines and equipment are the components of technological systems, v. 1, pp. 540-561 (2001)

7. A.V. Bogdanov, S.V. Ganenko, S.Y u. Popova, L.A. Shtricker. Substantiation of the necessity to improve plumping machine for processing fruit and vegetable raw materials, Chelyabinsk, pp.132-138 (2018)

8. A.V. Bogdanov, S.V . Ganenko, S.Y u. Popova, L.A. Shtricker (2018) Pulping machine, Patent A pplication No. RUS 179697 IC ${ }^{7}$ A23N 15/00 Chelyabinsk: South Ural State A grarian U niversity.

9. LPR R M -011-2000 Interindustrial rules on labor protection in public catering (2000)

10. V.D. Elkhina, M .I. Botov, Catering equipment. Mechanical equipment, v. 1, 416 p. (2010)

11. Physical properties of fruits and vegetable, doi: http://www.comodity.ru/agricul tural/fruitsvegetables/25.html

12. B.A. Voronyuk, A.I. Pyankov, et al. Physical and mechanical properties of plants, soils and fertilizers (1970)

13. A.V. M eshkov, S.V. Pustovalova, V.I. Terekhova, Methodological manual for making the tasks on plant breeding and seed production of vegetables on the subject "The study of testing features and the description of watermelon, melon, pumpkin, vegetable marrow and squash varieties" (2005)

14. B.M. Y avorskiy, A.A. Detlaf, A.K. L ebedev, Handbook of physics for engineers and students of universities (2006).

15. S.B. A fanasyev, A.A. A mericantsev, et al. A brief guide to physics (2017). 